\title{
MASTER OF SCIENCE IN COMPUTER AND INFORMATION SYSTEMS ENGINEERING
}

\author{
Satinderpaul Singh Devgan \\ Tennessee State University
}

\begin{abstract}
:
With the invention of transistor and the ensuing advances, we have moved into the information age. The information growth is phenomenal and companies with ready access to pertinent information in the appropriate form will have an advantage over their competition. Development of such systems is traditionally done by engineers with background in engineering or computer science and many years of on the job experience in systems engineering. To keep up with the phenomenal growth in information, there is growing need for engineers with background and experience in computer hardware and software and systems engineering. Most programs offered by universities are still traditional programs in major fields of engineering. However, there are a few programs that offer computer engineering, systems engineering and some combinations of these. Most of these programs prepare for software or hardware experiences but integration of systems requires different kind of knowledge such as systems engineering. This paper describes one such program that integrates systems engineering and prepares its graduates with background in computer hardware, software, and computer networks and communication. The program was developed with active participation of faculty and industrial representatives who reviewed the proposal and provided valuable input. The program requires 30 semester credit hours including six credit hours for thesis. The program has been developed to provide a basic background in the three areas and this will be strengthened by research projects in areas of student interest.
\end{abstract}

\section{Introduction}

According to the report of the National Critical Technology Panel of the Office of Science and Technology Policy (OSTP), two of the most critical technologies are manufacturing and information and communication. These two technologies include flexible manufacturing, computing and networking, software engineering, microelectronics and optoelectronics, data storage and computer modeling and simulation. The areas of communications, networking and information storage constitute major and rapidly growing segments of the industrial base. In the area of manufacturing, according to Dr. Clarence Nixon, Jr., Chief Information Officer, Alcoa World Wide Automotive, Southfield, MI, "the average cycle or concept-to-delivery time for the U.S. - based automaker is more than 36 months whereas Toyota Motors plans to reduce its current cycle or concept-to-delivery time from 17 months to 12 months." This will require a paradigm shift in the training and thinking of U.S. engineers to meet these types of challenges from worldwide competitors. This is just one example of U.S. companies looking for engineers with unique training to meet the challenges of the 21 st century. This training requires systematic 
approach to the design and development of a system(s) that integrates components, parts, computer hardware, software and systems from various platforms and vendors.

The outcome is the evolution of an emerging field of Computer and Information Systems Engineering (CISE). As an inter-disciplinary field, CISE comprises different aspects of computer science, electrical engineering and systems engineering. We believe the proposed program will provide the type of training needed to meet these challenges.

\section{Program Uniqueness:}

Most programs available today are either software only (CS), hardware only (EE), or in some cases a combination of both computer hardware and computer software $(\mathrm{CpE})$, but there is none to our knowledge that integrates systems engineering with hardware and software. Most major information system projects involve systematic integration of computer hardware, software and communication systems but very few engineering programs offer an integrated program. Most of the systems engineering training and experience is generally on the job. With the current competitive nature of business, there is hardly any time allowed for on-the-job training. Therefore, it is very important to combine the important concepts of systems engineering into an engineering program.

Systems Engineering involves systematic development or selection of a system or process through a four step process involving (1) Study Phase or Problem Identification, (2) Design Phase or Performance Definition Phase which includes general constraints, specific objectives and input/output description; (3) Development Phase or Feasibility Analysis, which involves preparing implementation plan, acquiring equipment and components, completion of computer programs, training of personnel, and completion of acceptance review; and (4) Operations Phase or System Recommendation, which involves planning and implementing phased in replacement, managing change, and performance evaluation ${ }^{1}$. The proposed M.S. in Computer and Information Systems Engineering (CISE) program in unique because it integrates the systematic approach to development of a system or process. This program will provide its graduates with a basic understanding of various computer architectures, from PC to main frame and from various vendors, provide an introduction to a variety of software and operating systems and an experience in using systems engineering approach to development of information and communication network systems such as an intelligent transportation system, a computer and communication network, or an information processing and retrieving system. We have received input and encouraging comments from some of the leading industries in this field during the development of this curriculum. We plan to expand their involvement in the further development and implementation of this program.

\section{National and Local Demand}

The following studies and programs provide sufficient evidence of potential growth and demand for professionals with background in the proposed area: 
In an increasingly competitive global market, with information as its common currency, businesses with accurate, secure and appropriate information systems will have definite advantage over its competition ${ }^{2}$.

The areas of communications, networking and information creation, storage and retrieval constitute major and rapidly growing segment of the U.S. industrial base ${ }^{3}$. By the turn of the $21^{\text {st }}$ century, nearly half of all the service workers will be involved in collecting, analyzing, synthesizing, structuring, sorting or refining information and the fastest growth for employment is projected to be for computer systems engineers and analysts ${ }^{4}$.

Our national critical technological goals include the development of National Information Infrastructure (NII) and the High Performance Computing and Communication (HPCC) where the areas of networking and computer communication are critical enabling technologies. Another evidence of national importance of a program in CISE is that NSF has created a Directorate for Computer and Information Science and Engineering (CISE) to fund research in the areas of communication, networking, system design, manufacturing and computer engineering and development of educational programs to meet professional needs for these programs.

Locally, Metropolitan Nashville is recognized as the health industry Mecca, and is also known for its insurance, music and religious publications industry. Columbia Health Services has its computer information center located in Nashville that provides the necessary information services to their wide network of hospitals and business centers. Nissan Motors and Saturn Manufacturing plants are the most modern manufacturing facilities and they rely heavily on computer engineers to maintain and upgrade their automated and flexible manufacturing systems to stay abreast of the competition. General Electric Information Services has moved their main operations to Nashville. EDS Systems here provides systems support for Nissan Manufacturing. They are always looking for engineers with background in Computer and Information Systems. According to the Research Unit of the Tennessee Department of Economic Development, the need for computer engineers and system analysts in the Davidson and surrounding counties will grow at the rate of $9.4 \%$ and $7.9 \%$ respectively every year till year $2005^{5}$. A recent survey of our students indicated that 65 percent will pursue graduate study if financial assistance was available. About $12.4 \%$ indicated that they will pursue M.S. in CISE program.

The goal of the Computer and Information Systems Engineering (CISE) program is to graduate engineers with training and experience in the systematic development of major information and communication systems to meet the needs of our Information Age society. Properly trained information systems professionals who understand how to fully integrate multi-disciplinary technologies and practices for end-user applications are and will continue to be in high demand in the labor market. At present, there are only handful of universities that offer a variety of electrical and information systems educational programs. To our knowledge there is none that offers a graduate degree program in CISE in the State of Tennessee.

\section{Admission Requirements}


This program will be open to graduates of accredited programs in areas of engineering, computer science and business. Each applicant's academic background will be evaluated to identify any prerequisites deficiencies.

For unconditional admission to the M.S. in CISE program, the student must have a B.S. degree in electrical engineering or computer science from an accredited program and the necessary prerequisite courses. In addition, the student must have a cumulative grade point average of 3.00 or above out of 4.00. Students with academic deficiencies and/or cumulative grade point average between 2.75 and 2.99 will be admitted conditionally. All prerequisites must be completed before taking a required graduate course in the area. Foreign students must demonstrate proficiency in English. The student must submit an Application for Admission, two copies of transcripts along with three letters of recommendations to the Dean of Graduate School.

\section{Enrollment Projections}

The M.S. degree program in Computer and Information Systems Engineering was approved by the Tennessee Higher Commission in August 1996. The projection for student enrollment during the first few years is low because it is a new program and is not yet well established. But if the $162 \%$ growth in enrollment in our concentration in Computers under the BSEE program is any indication, the enrollment figures will definitely be higher than these.

$\begin{array}{ccccc}\text { Year } & \text { Part-time } & \text { Full-time } & \text { FTE } & \text { Graduates. } \\ & \text { Head Count } & \text { Head Count } & \text { Students } & \\ 1996 & 3 & 4 & 5 & 0 \\ 1997 & 7 & 8 & 11 & 1 \\ 1998 & 11 & 13 & 19 & 5\end{array}$

A number of current and new graduate students have indicated interest in this program. We plan to advertise this program nationally during the Spring 1997.

\section{Industry Participation and Support}

Systems integration is practiced in industry but it is not taught in colleges or universities. Most systems engineers are traditionally engineering graduates who have gained systems engineering knowledge and experience as part of their work experience. We recognize that these experts are valuable to their organizations. We plan to seek their advice and invite these engineers as adjunct, visiting or full-time faculty to help us develop this unique program. During the developmental phase of the curriculum, we received input from a number of industrial representatives from the information industry and some have promised to help with its further development. 
It will take some time for our faculty to fully develop the curriculum and necessary course work. These experiences will be shared with others through publications. It is hoped that this will serve as a model curriculum for other universities.

\section{Benefit of Proposed Program to Industry}

In the 21st century, the success and survival of an organization will be determined by immediate access to correct and appropriate information. Most businesses will develop their own systems in stead of relying on turn-key operations. This program addresses the need for engineers with background in hardware, software and systems engineering. These successful organizations will need systems engineers.

There are no more than a few universities that offer similar programs. Partnership with Tennessee State University will provide the businesses an opportunity to influence the development of this program which could be easily transported to other institutions.

Industry will have ready access to trained systems engineering graduates and will not have to invest time and money in training. Tennessee State University has a long history of graduating highly qualified minority and female engineers. This will further contribute to the diversity of their professional work force.

\section{CISE Program of Study}

The CISE program is designed to provide fundamental background in hardware and software, communication and networks, and systems engineering. The program requires 30 credit hours for graduation which includes two elective courses and six credit hours of thesis. The educational experience is culminated with the development of an integrated system in the students' thesis. 
The course offering for this program are as follows:

Fall Semester

CISE 501

CISE 502

CISE 504
Data Structures and Algorithms

Computer Architecture \& Operating System

Systems Engineering
Cr. Hours

3

3

3

3

3

3

3

CISE 590a Master of Science Thesis I

\section{Fall Semester}

CISE 522 Computer Aided System Design 3

Elective 3

CISE 590b Master of Science Thesis II 3

\section{References}

1. Gore, M.R., and Stubble, J.W. Computers and Information Systems, McGraw Hill Book Co. New York, NY, 1984.

2. Shaping the Future - New Expectations for undergraduate education in Science, Mathematics, Engineering and Technology. Executive Summary of its Review of Undergraduate Education. Advisory Committee to the National Science Foundations, Directorate of Education and Human Resources. (NSF 96-141).

3. Cetron, M.J., “Career Direction during the '90's”. Journal of Career Planning and Employment. March 1990. Pp. 29-36.

4. “Projections 2000”, Bureau of Labor Statistics, U.S. Department of Labor, Bulletin\#2309, March 1988, pp. 5455.

5. "State of Tennessee Demand/Supply/Analysis - Employment Projections Report by Tennessee Occupational Information Coordinating Committee - Occupational Information”, Research and Statistics Division, Department of Employment Security, State of Tennessee, May 81996.

\section{APPENDIX}


Description of Courses

CISE 501 Data Structures and Algorithms (3): Files and data structures used in computing such as lists, etc.; techniques of storing and retrieving data such as hashing, indexing, etc.; relational data-base models, SQL databases and servers, and data-base management systems. Selection and design of algorithms, search and sorting techniques, pattern matching, mathematical problems. Prerequisite: CS 320, Engr 223 or equivalent.

CISE 502 Computer Architecture and Operating Systems (3): An understanding of capabilities, limitations and applications of different computer architectures of large supercomputers to smaller workstations. Basic computer resource management techniques, discussion of types of operating systems, distributed and parallel processing, real time programming and inquire-response systems. An overview of different implementations. Prerequisite: CS 411, CS 341 or EE 430 or equivalent.

CISE 503 Software Systems Design (3): Concept of software product life cycle, software design methodologies, stages in software development, metrics and models, reliability and reusability of code, software development tools, analysis, and design validation, small team projects involving architecture design and software specifications, computer aided software engineering (CASE). Prerequisite: EE 306L and CS 304 or EE 431.

CISE 504 Systems Engineering (3): To provide the student with the knowledge, support, and organization in developing a comprehensive information system including integration of hardware and software that successfully meets the needs of the organization. Data flow analysis, system modeling and optimization of business operations. Introduction to data-base design and decision support systems. Prerequisite: Engr 223, and 340 or equivalent.

CISE 505 Advanced Discrete Mathematics (3): Selected topics in discrete mathematics, formal systems, mathematical deduction, logical concepts, theorem proving sets, relations on sets, operations on sets, functions, graphs, mathematical structures, morphism, algebraic structures, semigroups, finite state machines and simulation, Kleene theorem. Prerequisite: CS 320 or equivalent.

CISE 506 Error Control Codes (3): Introduction to codes for error detection and correction, linear algebra over finite fields, bounds, perfect and quasi-perfect codes, probability of error checking, Hamming, $\mathrm{BCH}$, MDS, Reed-Solomon codes, and non-linear codes. Prerequisite: CS 320, EE 350 or equivalent.

CISE 5 I1 Artificial Intelligence/Expert Systems (3): Case studies in artificial intelligence, design and use of expert system shells, etc. This course will .be operated as a project oriented course which utilizes many existing artificial intelligence techniques. Prerequisite: EE 306L or equivalent. 
EE 503 Artificial Neural Networks (3): Introduction to Neural Networks, its development history, concept of connectionism, neuron models, structure of neural networks, learning strategies, content addressable memory, design and applications of neural networks and other pertinent topics. Prerequisite: Math 303, Engr 340 or equivalent.

CISE 522 Computer Aided Systems Design (3): Advanced computer-aided analysis and design tools for analysis of system properties and performance, study of structure and theory of computer aided design software and hardware, and the small scale design of such tools. Prerequisites: EE 310, 310L, CISE 501 and CS 504 or equivalent.

CISE 523 Computer Communication and Networks (3): Review of theory of various information and communication systems and current trends in the application of computers and information networks in their design. Topics include - an introduction to digital communication, control of data transmission over communication lines, data acquisition through smart sensors, scanners and wireless communications, and user interface design including graphical and interactive multi-media. The ISO layered network protocol, network topology, packet switching, routing, network management, discussion of narrowband and broadband ISDN. Application of basic traffic theory, switching fundamentals and routing strategies. Prerequisite: EE 321, 350 or equivalent.

CISE 524 Management of Information Systems (3): This course will discuss current methods in use for the design and implementation of modern information technology in organizational systems. It will also provide a comprehensive introduction to basic principles of the legal, economic, and regulatory environment of the information industry. Prerequisite: ME 502 , EE 350 or equivalent.

EE 524 Digital Communication (3): Digital communication concepts, channel characterization, base-band pulse transmission, coherent and non-coherent digital signaling, inter symbol interference, base-band shaping, equalization, synchronization and detection, error-control codes, modems, and terminals. Prerequisite: EE 330, 350, or equivalent.

CISE 530 Robotics and Automation (3): Transformation techniques, manipulator kinematics, Jacobian, dynamics, position and force controls, robot programming languages and systems, control problems in robotics and industrial automation, numerical controls, computer aided controls. Prerequisite: EE 400 and instructor's approval

CISE 540 Special Topics in CISE (3): Recent advanced topics in Computer and Information Systems Engineering will be studied based on faculty and students' needs. Prerequisite: instructor's approval.

CISE 590a Master of Science Thesis I. (3) Thesis topics to be selected in consultation with the chairman of thesis committee and approval of the department head. The thesis will involve hardware, software and systems approach to the design and development of an integrated 
system. About 50 percent of the thesis must be completed before a letter grade is awarded. Prerequisite: Admission to Candidacy.

CISE 590b Master of Science Thesis II. (3) Continuation and completion of thesis and oral presentation defense. Prerequisite: CISE 590a. 